\title{
A CONTRIBUIÇÃO DAS DEMONSTRAÇÕES CONTÁBEIS NO PROCESSO DE CONCESSÃO DE CRÉDITO: UM ESTUDO DE CASO DO MUNICÍPIO DE SÃO PAULO
}

\section{THE CONTRIBUTION OF FINANCIAL STATEMENTS IN THE GRANTING CREDIT PROCESS: A CASE STUDY OF SÃO PAULO CITY}

Recebido: 04/04/2016 - Aprovado: 15/06/2016 - Publicado: 10/12/2016 Processo de Avaliação: Double Blind Review

\author{
Sergio Roberto da Silva ${ }^{1}$ \\ Mestre em Ciências Contábeis pela \\ Fundação Escola de Comércio Álvares Penteado- FECAP \\ sergioroberto@auditaconsultoria.com.br \\ Adriana Cabral Rodrigues \\ Graduada em Processos Gerenciais \\ Universidade Norte do Paraná \\ drica_1703@yahoo.com.br \\ Luís Alberto Pinto Gomide \\ Bacharel em Administração de Empresas \\ Universidade Prebiteriana Mackenzie \\ luis@ reebokclub.com.br \\ Márcia Welita da Silva \\ Graduada em Administração \\ Mestrado Profissional em Administração de Empresas \\ Centro Universitário das Faculdades Metropolitanas Unidas - FMU \\ mwelita@hotmail.com
}

\section{RESUMO:}

O processo de análise de concessão de crédito é importante para o desenvolvimento de qualquer país. Esta pesquisa busca descrever a utilização da análise de demonstrações contábeis dentro do contexto do processo de concessão de crédito das instituições financeiras.

\footnotetext{
${ }^{1}$ Autor para correspondência: Fundação Escola de Comércio Álvares Penteado Av. da Liberdade, 532, Liberdade, São Paulo, SP, Brasil, CEP: 01502-001
} 
Propõe-se aqui, identificar a relevância da informação contábil para a análise de crédito e como esta informação influencia a decisão final.Procurou-se estabelecer uma conclusão acerca dessa importância, realizando-se estudo de casos através da aplicação de entrevistas com profissionais da área de crédito de instituições financeiras distintas, sediadas no município de São Paulo. Utilizou-se como técnica desta pesquisa entrevistas semiestruturadas atreladas a um protocolo de pesquisa. A Pesquisa revela que as demonstrações contábeis representam $70 \%$ da opinião da concessão de crédito e, além das demonstrações, os bancos utilizam-se de outras ferramentas para conceder ou não o crédito. Conclui-se que os preceitos de realização das demonstrações contábeis devem ser seguidos com o objetivo de não prejudicar as organizações em uma eventual solicitação de crédito junto às instituições financeiras.

Palavras-chave: Análise de Balanços; Análise de Crédito; Concessão de Crédito. Indicadores; Qualidade da Informação.

\section{ABSTRACT:}

The granting credit analysis process is important to the development of any country. This research aims to describe the use of financial statement analysis within the context of the financial institutions credit granting process. We propose to identify the relevance of accounting information for credit analysis and how this information influences a final decision. We tried to establish a conclusion of this importance, performing case studies by applying interview with credit professionals from different financial institutions headquartered in São Paulo. The research technique was the semi-structured interview tied to a research protocol. Research reveals that the financial statements represent $70 \%$ of the opinion of the credit granting. In addition to the statements the banks are used other tools to grant or not the credit. It follows that the principles of realization of the financial statements must be followed in order to not harm the organizations in any credit application with financial institutions 
Keywords: Balance Sheet Analysis; Credit Analysis; Credit Granting; Indicators. Information Quality.

\section{INTRODUÇÃO}

Segundo Assaf Neto (2010, p.35), a análise das demonstrações financeiras é uma fonte de extração de informações sobre a vida econômica e financeira das entidades. É através destas informações que grande parte das instituições concessoras de crédito baseiam-se para liberar ou não uma solicitação de crédito.

A análise de demonstrações contábeis, dentro do contexto creditício proposto, tende a indicar a possibilidade e grau de inadimplência das empresas analisadas, tornando mais evidente a probabilidade, ou não, de pagamento dos seus financiamentos.

Vale ressaltar que, na atual conjuntura financeira, a análise de crédito não se baseia apenas em avaliar a possível liquidação de endividamento adquirido, mas também o futuro financeiro da empresa, verificando sua expectativa de rentabilidade e seu grau de solvência, buscando avaliá-la também em longo prazo, de forma a identificar um potencial cliente a se manter.

Diante disso, a questão identificada para esta pesquisa é:

Qual a contribuição da análise das demonstrações contábeis no processo de concessão de crédito das instituições financeiras?

O objetivo geral deste trabalho é identificar qual a influência da análise das demonstrações contábeis para o processo de concessão de crédito. O Quadro 01 apresenta a relação entre as questões a serem respondidas na pesquisa e os objetivos específicos. 
Quadro 01- Relação entre questões investigativas e objetivos específicos. Autor: Elaborado pelos autores.

\begin{tabular}{|l|l|l|}
\hline Item & Questões investigativas & Objetivos específicos \\
\hline 1 & $\begin{array}{l}\text { Quais as informações mais comuns extraídas das } \\
\text { demonstrações contábeis que influenciam na } \\
\text { análise e liberação de crédito? }\end{array}$ & $\begin{array}{l}\text { Identificar o que a análise das demonstrações } \\
\text { contábeis fornece para a análise de crédito e qual } \\
\text { a importância dessas informações. }\end{array}$ \\
\hline 2 & $\begin{array}{l}\text { Quais os riscos identificados pelos participantes } \\
\text { relacionados à confiabilidade e qualidade das } \\
\text { informações existentes nas demonstrações? }\end{array}$ & $\begin{array}{l}\text { Identificar quando as informações são } \\
\text { consideradas confiáveis, analisar se a fonte da } \\
\text { demonstração contábil contribui para sua } \\
\text { confiabilidade ou não. }\end{array}$ \\
\hline 3 & $\begin{array}{l}\text { Quais outros fatores influenciam na decisão de } \\
\text { um processo de concessão de crédito, e qual o } \\
\text { grau de participação da análise de de } \\
\text { demonstrações contábeis neste contexto? }\end{array}$ & $\begin{array}{l}\text { Verificar se existem outros fatores a serem } \\
\text { avaliados num processo de decisão de crédito, e } \\
\text { participação da análise das demonstrações } \\
\text { contábeis neste contexto. }\end{array}$ \\
\hline
\end{tabular}

Fonte: Elaborado pelos autores, 2016.

As proposições deste trabalho são apresentadas no Quadro 02.

QUADRO 02- Relação entre questões investigativas e proposições do trabalho. Autor: Elaborado pelos autores.

\begin{tabular}{|c|c|c|}
\hline Item & 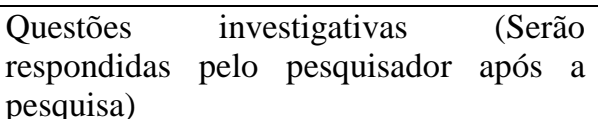 & Proposição \\
\hline 1 & $\begin{array}{l}\text { Quais as informações mais comuns } \\
\text { extraídas das demonstrações contábeis } \\
\text { que influenciam na análise e liberação de } \\
\text { crédito? }\end{array}$ & $\begin{array}{l}\text { A análise das demonstrações contábeis fornece } \\
\text { informações importantes e decisivas em um processo de } \\
\text { crédito. } \\
\text { A análise das demonstrações contábeis não fornece } \\
\text { informações importantes e decisivas num processo de } \\
\text { crédito. }\end{array}$ \\
\hline 2 & $\begin{array}{lcr}\text { Quais os riscos } & \text { identificados } & \text { pelos } \\
\text { participantes } & \text { relacionados } & \text { à } \\
\text { confiabilidade } & \text { e } \quad \text { qualidade } & \text { das } \\
\text { informações } & \text { existentes } & \text { nas } \\
\text { demonstrações? } & & \end{array}$ & $\begin{array}{l}\text { As informações geradas pela análise das demonstrações } \\
\text { contábeis são consideradas confiáveis, e por isso } \\
\text { fundamental para o processo de concessão de crédito. } \\
\text { As informações geradas pela análise das demonstrações } \\
\text { contábeis não são consideradas confiáveis, e por isso } \\
\text { não são fundamentais para o processo de concessão de } \\
\text { crédito. }\end{array}$ \\
\hline 3 & $\begin{array}{l}\text { Quais outros fatores influenciam na } \\
\text { decisão de um processo de concessão de } \\
\text { crédito, e qual o grau de participação da } \\
\text { análise de demonstrações contábeis neste } \\
\text { contexto? }\end{array}$ & $\begin{array}{l}\text { Existem diversos outros fatores a serem considerados de } \\
\text { forma relevante neste processo de crédito. } \\
\text { Os outros fatores analisados não fornecem informações } \\
\text { decisivas neste processo, sendo apenas fatores } \\
\text { complementares. }\end{array}$ \\
\hline
\end{tabular}

Fonte: Elaborado pelos autores, 2016.

A escolha do tema, baseia-se na cotidiana solicitação de crédito por parte das empresas, incluindo empresas do varejo. Além deste fato, a pesquisa busca resgatar e compartilhar a importância de informar todos os fatos contábeis da administração ao profissional de contabilidade, para que o mesmo prepare relatórios contábeis condizentes com a realidade da empresa, uma vez que dados faltantes ou incompletos poderão ocasionar em uma negativa na tentativa de um empréstimo. 


\section{REFERENCIAL TEÓRICO}

É importante se atentar ao fato de que, por conta da conceituação dada por diversos autores, a análise das demonstrações contábeis é denominada em muitas situações apenas como análise de balanços.

Para a análise das demonstrações contábeis, segundo Assaf Neto (2010, p.36), os relatórios obrigatórios elaborados periodicamente pelas empresas torna-se um insumo básico. Esses relatórios periódicos são apresentados no Quadro 3.

Quadro 3- Relatórios contábeis.

\begin{tabular}{|c|c|}
\hline Relatório & Conceito \\
\hline $\begin{array}{l}\text { Balanço } \\
\text { Patrimonial }\end{array}$ & $\begin{array}{l}\text { Segundo Assaf Neto }(2010, \text { p.45), o balanço patrimonial é a representação da posição } \\
\text { patrimonial e financeira da empresa, sendo composto de três partes: o ativo, passivo e } \\
\text { patrimônio líquido; O ativo relaciona as aplicações de recursos efetuadas pela empresa; O } \\
\text { passivo indica as exigibilidades e obrigações da empresa; O patrimônio líquido é a } \\
\text { diferença entre os itens anteriores, e representa os recursos investidos pelos acionistas da } \\
\text { empresa (capital) e os lucros retidos gerados pela empresa, ou seja, são os recursos } \\
\text { próprios da empresa. }\end{array}$ \\
\hline $\begin{array}{l}\text { Demonstração } \\
\text { de Resultado }\end{array}$ & $\begin{array}{l}\text { Assaf Neto }(2010, \text { p. 64) destaca que a demonstração de resultados do exercício visa } \\
\text { fornecer, de maneira esquematizada, os resultados (lucro ou prejuízo) auferidos pela } \\
\text { empresa em determinado exercício social, os quais são transferidos para contas do } \\
\text { patrimônio líquido. O lucro (ou prejuízo) é resultante de receitas, custos e despesas } \\
\text { incorridos pela empresa no período e apropriados segundo o regime de competência, ou } \\
\text { seja, independentemente de que tenham sido esses valores pagos ou recebidos. }\end{array}$ \\
\hline $\begin{array}{l}\text { Demonstração } \\
\text { das Mutações } \\
\text { de Patrimônio } \\
\text { Líquido }\end{array}$ & $\begin{array}{l}\text { É mais completa do que as Demonstrações de Lucros ou Prejuízos Acumulados, pois, } \\
\text { assim como define Assaf Neto (2010. P.78), a primeira citada pode substituir a segunda, } \\
\text { pois abrange todas as contas do Patrimônio Líquido, indicando todas as variações e } \\
\text { movimentações ocorridas nessas contas. }\end{array}$ \\
\hline $\begin{array}{l}\text { Demonstração } \\
\text { de Fluxo de } \\
\text { Caixa }\end{array}$ & $\begin{array}{l}\text { Surge em substituição à Demonstração da Origem e Aplicação de Recursos, a DOAR, que } \\
\text { fornecia a descrição da origem dos recursos da empresa e onde eram aplicados. A } \\
\text { Demonstração de Fluxo de Caixa, segundo Ferrari (2006, p.210), demonstra as variações } \\
\text { ocorridas no grupo de disponibilidades da empresa, descrevendo os fluxo de entrada e } \\
\text { saída de disponibilidade, ou recebimentos e pagamentos. }\end{array}$ \\
\hline $\begin{array}{l}\text { Demonstração } \\
\text { do Valor } \\
\text { Adicionado - } \\
\text { DVA }\end{array}$ & $\begin{array}{l}\text { Segundo Ferrari (2006, p. 246), o DVA tem por objetivo demonstrar qual a riqueza criada } \\
\text { por uma empresa no exercício analisado e a forma como essa riqueza foi distribuída para } \\
\text { empregados, bancos, financiadores, governo, sócios e a parcela de lucro retida pela } \\
\text { empresa. }\end{array}$ \\
\hline $\begin{array}{l}\text { Parecer de } \\
\text { Auditoria, e o } \\
\text { Relatório de } \\
\text { Administração }\end{array}$ & $\begin{array}{l}\text { São também duas peças importantes. Segundo Assaf Neto (2010, p. 37-38), o Relatório de } \\
\text { Administração possui informações de caráter geral de empresa, como projeções } \\
\text { financeiras, projeto de expansão, perspectivas de mercado, dentre outras; O Parecer de } \\
\text { Auditoria indica a adequação das demonstrações contábeis com a real situação da } \\
\text { empresa, onde os comentários do auditor atribuem maior segurança aos analistas de } \\
\text { balanços, valorizando a qualidade da informação. }\end{array}$ \\
\hline
\end{tabular}

Fonte: Elaborado pelos autores, 2016. 
Segundo Assaf Neto (2010, p.45): "Somente pelo entendimento da estrutura contábil das demonstrações é que se pode desenvolver avaliações mais acuradas das empresas".

Os princípios da história da Contabilidade de baseiam na necessidade de manter o controle sobre os bens dos indivíduos e sobre as operações de troca. Hoje em dia, a contabilidade e a sua correta análise, fornecem dados sobre a real situação financeira de uma empresa e vem ganhando espaço no contexto empresarial atual.

Os dados contábeis passam a gerar informação, encaixando-se neste contexto a análise de balanços. Para contextualizar de forma mais clara, é válido destacar a seguinte definição da análise de balanços:

As demonstrações financeiras mostram, por exemplo, que a empresa tem $\$ \mathrm{Y}$ milhares de dívida. Isto é um dado. A conclusão de que a dívida é excessiva ou é normal, de que a empresa pode ou não pagá-la é informação. O objetivo da Análise de Balanços é produzir informação. (MATARAZZO, 2003, p. 16).

A análise de balanços é um instrumento capaz de traçar o perfil financeiro da empresa ao longo do tempo e prever seu potencial futuro.

\begin{abstract}
A análise de balanços visa relatar, com base nas informações contábeis fornecidas pelas empresas, a posição econômico-financeira atual, as causas que determinaram a evolução apresentada e as tendências futuras. Em outras palavras, pela análise de balanços extraem-se informações sobre a posição passada, presente e futura (projetada) de uma empresa. (ASSAF NETO, 2010, p. $35)$.
\end{abstract}

Muitas são as finalidades da análise de balanços, tendo essa pesquisa foco na utilização dessa ferramenta para o processo de concessão de crédito.

Como aborda Sá (2008, p.18), a análise de crédito não é a única finalidade a que se dá a análise de balanços, essa ferramenta é também de utilidade para outras necessidades, como analisar a eficiência e prosperidade de um empreendimento, a sua vitalidade, ou seja, como cumpre seus objetivos e que perspectiva tem.

A análise vertical e horizontal são duas ferramentas que se baseiam na comparação de resultados de uma empresa, e na comparação da evolução de seu patrimônio. Para melhor compreender essa funcionalidade, vale destacar a definição de Assaf Neto (2010, p.93):

As duas principais características de análise de uma empresa são a comparação dos valores obtidos em determinado período com aqueles levantados em períodos anteriores e o relacionamento desses valores com outros afins. Dessa maneira, 
pode-se afirmar que o critério básico que norteia a análise de balanços é a comparação. (ASSAF NETO, 2010, p. 93).

Ainda segundo Assaf Neto (2010, p.42), verifica-se que a avaliação de um índice de forma isolada não é suficiente para uma correta conclusão.

Com base nesse conceito, é importante identificar separadamente as duas vertentes dessa comparação. A análise vertical é responsável por comparar resultados da empresa dentro do mesmo período, enquanto que a análise horizontal baseia-se na comparação de resultados em períodos distintos, na evolução patrimonial e de resultados da empresa.

Benedicto e Padoveze (2005, p.25) fazem uma definição de análise vertical e apontam que: "ela representa a análise da estrutura dos elementos das demonstrações contábeis onde assume-se como $100 \%$ um determinado elemento patrimonial, o que for considerado o mais importante, e o relacionam aos demais elementos sobre ele".

Ainda sobre o assunto, Ferrari (2006, p. 47) destaca a metodologia da comparação realizada pela análise vertical: "tal comparação consiste na determinação dos resultados obtidos pela operação matemática de divisão entre os valores das partes componentes das demonstrações e os totais de mesma natureza referentes às respectivas demonstrações".

Já quanto à análise horizontal, se refere a uma análise sobre os resultados ao longo de um período onde são avaliadas a evolução e as tendências de evolução das contas patrimoniais e de resultado ao longo dos períodos analisados. Essa análise pode ser aplicada ao conjunto das demonstrações contábeis, como explica Assaf Neto (2010, p.97), sendo ela importante por permitir uma avaliação das tendências passadas e futuras da empresa, onde é possível perceber que muitas vezes a atualidade financeira da empresa é afetada por fatores ocorridos em períodos anteriores, e que poderão refletir-se no futuro.

Os indicadores de análise de balanços são apresentados no Quadro 04.

Quadro 04 - Indicadores de análise de balanços. Autor: Elaborado pelos autores.

REMIPE- Revista de Micro e Pequenas Empresas e Empreendedorismo da Fatec Osasco V. 2, N`2, jul.-dez. 2016 


\begin{tabular}{|l|l|}
\hline Indicador & Descrição \\
\hline Liquidez & $\begin{array}{l}\text { Segundo Marion (2006, p.83), os índices de liquidez são utilizados para avaliar a } \\
\text { capacidade da empresa em saldar seus compromissos; Pode ser avaliado em curto prazo, } \\
\text { longo prazo, ou prazo imediato. }\end{array}$ \\
\hline Endividamento & $\begin{array}{l}\text { Estes quocientes relacionam as fontes de fundos entre si, procurando relacionar a } \\
\text { posição relativa do capital próprio ao capital de terceiros. São quocientes de muita } \\
\text { importância, pois indicam a relação de dependência da empresa ao capital de terceiros. } \\
\text { (IUDÍCIBUS, 2009, p. 97) }\end{array}$ \\
\hline Lucratividade & $\begin{array}{l}\text { Iudícibus (2009, p. 105) descreve: Devemos relacionar um lucro de um empreendimento } \\
\text { com algum valor que expresse a dimensão relativa do mesmo, para analisar quão bem se } \\
\text { saiu a empresa em determinado período. O melhor conceito de dimensão poderá ser ora } \\
\text { volume de vendas, ora valor do ativo total, ora valor do patrimônio líquido, ou valor do } \\
\text { ativo operacional, dependendo da aplicação que fizermos. }\end{array}$ \\
\hline
\end{tabular}

Fonte: Elaborado pelos autores, 2016.

As operações de crédito se dão pela necessidade das empresas em financiar suas operações, planejar sua expansão, e investir o capital de terceiros, visando seu crescimento.

Vale destacar a seguinte denominação, um pouco mais conceitual, dada por Pereira (1998, p. 24), segundo ele, as empresas tomam recursos no mercado para realizar investimentos, cujo objetivo é gerar lucratividade e uma margem de capital, que seria a diferença entre o ganho obtido no futuro por esse investimento e o ganho atual.

A seguir, uma denominação mais prática sobre o processo de concessão de crédito.

(...) análise de crédito é um processo organizado para analisar dados, levando às questões certas, assistindo no desenvolvimento de alternativas e apoiando solicitações de julgamento. Esse processo cobre uma estrutura mais ampla do que analisar o crédito de um cliente e dados financeiros para tomada de decisão com propósitos creditícios. A análise de crédito também inclui análises internas para identificar a própria situação financeira de uma empresa credora (...). (MONDINI, 2005, p. 33).

No processo de concessão de crédito para empresas, é necessário que sejam avaliados todos os aspectos que norteiam a situação da empresa analisada.

Para a análise da empresa, é necessário se valer de informações cadastrais que fornecem maior segurança para a liberação ou não de crédito. Neste sentido, Mondini (2005, p. 34) explica: "o cadastro é um conjunto de dados e informações a respeito das pessoas físicas ou jurídicas, que permitem à instituição conceder créditos com níveis de segurança almejados, desde que conjugados com outros tipos de informações".

Ainda segundo Mondini (2005, p.37), outra ferramenta importante na análise de crédito é a análise setorial da empresa, onde se deve avaliar o desempenho da empresa em 
relação ao desempenho do setor ao qual está inserida, sendo necessário que essa análise seja acompanhada constantemente, através de dados publicados pela imprensa, em publicações especializadas, dentre outros.

Além da análise cadastral e setorial, é de suma importância a análise da situação financeira da empresa, através da análise de suas demonstrações contábeis, que fornecerão a base para identificação de sua estrutura patrimonial. Sobre as informações dadas por essa análise, Mondini (2005, p.44) explica que: “os dados contábeis analíticos fornecem a avaliação do potencial da empresa, com referência aos créditos, seu grau de liquidez a curto prazo, bem como a sua capacidade de saldar seus compromissos a longo prazo".

Para a análise das demonstrações no processo de crédito, é necessário se ater à origem das informações onde, segundo Sá (2008, p.41), as principais fontes de informação são as publicações de balanços, mas também é comum o envio das demonstrações para análise pelos próprios credores e financiadores, que possuem cópias autenticadas em registros do comércio ou cartório.

As instituições de crédito, para a avaliação de um processo de concessão de crédito, buscam se cercar de todas as informações que norteiam a empresa e seu histórico de credora, e é dessa forma que conseguem reduzir cada vez mais os riscos de crédito.

É válido ressaltar o que Assaf Neto (2010, p.36) expões sobre o profissional da análise das demonstrações, segundo o qual, a utilização dos indicadores de análise é particular de quem realiza a análise, não sendo considerado apenas conhecimento técnico, mas também a experiência e intuição do analista.

\section{METODOLOGIA CIENTÍFICA}

Esta parte do estudo abordou um relato sistêmico a sobre o tema a ser investigado. O Quadro 05 apresenta resumidamente esta estrutura. 
Quadro 05- Resumo da pesquisa a ser desenvolvida. Autor: Elaborado pelos autores.

\begin{tabular}{|c|c|}
\hline Propósito & $\begin{array}{l}\text { Pesquisa aplicada. Neste caso, Abramo (1988, p. 35) assinala que este tipo de pesquisa "é feita } \\
\text { para que seus resultados tenham utilização imediata na solução de problemas concretos; é a } \\
\text { obtenção do conhecimento para transformação da realidade". Roesch (1996, p. 78) } \\
\text { complementa "a pesquisa aplicada refere-se à discussão de problemas, utilizando o referencial } \\
\text { teórico de determinada disciplina, e à apresentação de soluções alternativas". É o que os } \\
\text { autores propõem buscando o referencial para o atual assunto em questão. }\end{array}$ \\
\hline $\begin{array}{l}\text { Método de } \\
\text { intervenção }\end{array}$ & $\begin{array}{l}\text { Estudo de caso. O estudo de caso (YIN, 2006) foi escolhido compreender um fenômeno } \\
\text { localizado. Segundo Martins (2008), o Estudo de Caso é um método original e revelador, pois } \\
\text { analisa uma situação complexa da vida real e cada pesquisador pode descobrir novas } \\
\text { perspectivas que ainda não tinham sido abordadas por estudos semelhantes. }\end{array}$ \\
\hline Abordagem & $\begin{array}{l}\text { Exploratório. Teles (2001, p.84) define que pode ser associado às pesquisas, cuja abordagem } \\
\text { pretende desenvolver, aperfeiçoar ou rever conceitos, percepções ou visões, de modo a } \\
\text { disponibilizar maiores conhecimentos sobre a situação analisada, facilitando a estruturação, } \\
\text { mais precisa de futuros estudos. Especialmente é o caso do estudo em questão. Retomar o } \\
\text { assunto "Análise de Crédito" e abordar como as demonstrações contábeis contribuem neste } \\
\text { processo. } \\
\text { Segundo Gil (1996, p. 45), as pesquisas exploratórias "têm como objetivo proporcionar maior } \\
\text { familiaridade com o problema, com vistas a torná-lo mais explícito ou a construir hipóteses. } \\
\text { Pode-se dizer que estas pesquisas têm como objetivo principal o aprimoramento de ideias ou a } \\
\text { descoberta de instituições". Tal afirmação converge com os objetivos da pesquisa } \\
\text { Para Cooper e Schindler (2003, p. } 131) \text {, um estudo exploratório "é particularmente útil quando } \\
\text { os pesquisadores não têm ideia clara dos problemas que vão enfrentar durante o estudo". Esta } \\
\text { opinião é compartilhada por Hair, Babin, Money e Samouel (2005, p. 84). Isso é o que se } \\
\text { passou ao ser realizada a revisão da bibliografia e buscar novas descobertas no processo de } \\
\text { concessão de crédito. }\end{array}$ \\
\hline $\begin{array}{l}\text { Procediment } \\
\text { os } \\
\text { Qualitativos } \\
\text { ou } \\
\text { quantitativos }\end{array}$ & $\begin{array}{l}\text { Qualitativa. Para Teles (2001,p. 84), pode ser definida como aquela cujos objetivos estão } \\
\text { essencialmente concentrados no entendimento ou no reconhecimento de elementos conceituais, } \\
\text { relações e estruturas de interações entre estes elementos ou entidades, consideração ou } \\
\text { proposta de conceitos e/ou modelos, identificação de percepções e razões de preferencial, de } \\
\text { tal modo que os nexos de causalidade ou mesmo de correlação não estejam suficientemente } \\
\text { estruturados (em situação de serem considerados objeto de análise). Em decorrência desta } \\
\text { configuração, é possível a identificação de algumas características peculiares da pesquisa } \\
\text { qualitativa, como utilização de pequenas amostras (sem a necessidade de representatividade), } \\
\text { adoção de processos de coleta de dados diferenciados de questionários estruturados, } \\
\text { necessidade de compreensão dos problemas e objetivos da pesquisa e uso destes como dados } \\
\text { na definição do trabalho de campo e a possibilidade de os entrevistados expressarem } \\
\text { espontânea e individualmente sua escolha. } \\
\text { Para Godoy (1995, p. 62), a pesquisa qualitativa é descritiva, o mesmo ainda afirma que "a } \\
\text { palavra escrita ocupa lugar de destaque nessa abordagem, desempenhando um papel } \\
\text { fundamental no processo de obtenção dos dados quanto na disseminação dos resultados. }\end{array}$ \\
\hline $\begin{array}{l}\text { Campos de } \\
\text { atividade } \\
\text { humana }\end{array}$ & $\begin{array}{l}\text { Interdisciplinar. Segundo Chaves (2004 apud POHLMANN, 2005, p. 47): deve ser reservado } \\
\text { para designar o nível em que a interação entre várias disciplinas ou setores heterogêneos de } \\
\text { uma mesma ciência conduz a interaçôes reais, a uma certa reciprocidade no intercâmbio que } \\
\text { leva a um enriquecimento mútuo. Este é especialmente o caso deste trabalho, quando foram } \\
\text { relacionadas Contabilidade, Finanças e Administração, sem esquecer das ferramentas para tal } \\
\text { fim: Tecnologia da Informação e comunicação. }\end{array}$ \\
\hline $\begin{array}{l}\text { Natureza dos } \\
\text { dados }\end{array}$ & $\begin{array}{l}\text { Primário em virtude das conclusões e análises realizadas serem baseadas em dados extraídos } \\
\text { das entrevistas. }\end{array}$ \\
\hline $\begin{array}{ll}\text { Pesquisa } & \text { ao } \\
\text { longo } & \text { do } \\
\text { tempo } & \end{array}$ & Será realizada coleta de dados em um único momento. \\
\hline $\begin{array}{ll}\text { Extensão } & \text { do } \\
\text { campo } & \text { de } \\
\text { estudo } & \end{array}$ & $\begin{array}{l}\text { Pesquisa monográfica. Para Abramo (1988,p.39), as pesquisas monográficas e de } \\
\text { profundidade referem-se a limitação da pesquisa a um tema ou a um problema específico, o } \\
\text { exame do maior número possível de variáveis que interfiram no tema ou no problema de } \\
\text { pesquisa. }\end{array}$ \\
\hline
\end{tabular}




\begin{tabular}{|c|c|}
\hline $\begin{array}{l}\text { Relação entre } \\
\text { pesquisador e } \\
\text { a pesquisa }\end{array}$ & $\begin{array}{l}\text { Não-participante. Para Abramo (1988,p.39), o pesquisador se coloca em situação de espaço } \\
\text { e tempo que lhe permita assistir às manifestações do fenômeno a ser estudado, podendo } \\
\text { utilizar várias formas de registro das suas observações: caderneta de campo, fichas, } \\
\text { instrumento de medidas, gravadores, filmadoras, máquinas fotográficas, dentre outros. }\end{array}$ \\
\hline $\begin{array}{l}\text { Quantidade de } \\
\text { casos }\end{array}$ & Três instituições financeiras (bancos) distintas. \\
\hline $\begin{array}{ll}\text { Critério } & \text { de } \\
\text { escolha } & \end{array}$ & $\begin{array}{l}\text { Para a definição dos entrevistados, serão seguidos os seguintes critérios: } \\
\text { 1- Instituições de crédito localizadas no município de São Paulo; } \\
\text { 2- Instituições que executem o processo de análise de crédito especialmente ao varejo; } \\
\text { 3- Instituições com profissionais que aceitaram fazer a pesquisa. }\end{array}$ \\
\hline $\begin{array}{ll}\text { Unidade } & \text { de } \\
\text { análise }\end{array}$ & O processo de análise de crédito às pessoas jurídicas do varejo \\
\hline $\begin{array}{l}\text { Total de horas } \\
\text { de entrevista }\end{array}$ & 385 minutos (6 horas e 25 minutos) \\
\hline $\begin{array}{lr}\text { Métodos } & \text { de } \\
\text { coleta } & \text { dos } \\
\text { resultados } & \end{array}$ & Entrevista semi-estruturada com protocolo de pesquisa. \\
\hline $\begin{array}{ll}\begin{array}{l}\text { Sujeito } \\
\text { pesquisa }\end{array} & \text { da } \\
\end{array}$ & Analistas de crédito das instituições financeiras. \\
\hline $\begin{array}{lr}\text { Descrição } & \text { dos } \\
\text { métodos } & \text { de } \\
\text { análise } & \text { dos } \\
\text { dados } & \end{array}$ & Análise de conteúdo. \\
\hline
\end{tabular}

Fonte: Elaborado pelos autores, 2016.

\section{APRESENTACÃO E DISCUSSÃO DOS RESULTADOS}

Para o cumprimento do objetivo proposto, foi utilizada a técnica da Triangulação para a discussão dos dados. Esta técnica visa aumentar a confiabilidade dos dados. Martins e Theophilo (2009), afirmam que a convergência de resultados advindos de fontes distintas oferece um excelente grau de confiabilidade ao estudo, muito além da pesquisa orientada por outras estratégias.

Desta forma, esta parte do estudo irá comparar os resultados desta pesquisa que, aliado à literatura e pesquisas colocadas no referencial teórico, permitirão chegar à conclusões coerentes que serão expostas no capítulo seguinte.

A forma de apresentação vai considerar os objetivos propostos. 


\section{1- A Contribuição da Análise das Demonstrações Contábeis para Concessão De Crédito}

Perguntou-se aos entrevistados: De forma geral, as análises das demonstrações contábeis (análise vertical/horizontal, comparação de períodos) fornecem informações adequadas à concessão de crédito?

No referencial teórico, foi visto que a análise das demonstrações contábeis deve ser baseada em fontes de informações contábeis confiáveis, onde sejam analisados no mínimo três períodos, e sejam realizadas análises verticais e horizontais, e não só a aplicação dos indicadores de análise.

Ao analisar as respostas, verificou-se que a análise das demonstrações contábeis é feita contemplando no mínimo os três últimos períodos das demonstrações, sendo importante também a realização da análise vertical e horizontal e do cálculo dos indicadores financeiros.

A comparação desta questão com o referencial teórico foi positiva.

Ao comparar os resultados acima com a pesquisa de Assaf Neto (2010), onde afirma que a análise de balanços é fundamentalmente comparativa, sendo a avaliação isolada de determinado índice insuficiente para se produzir uma correta avaliação, identifica-se que os dados são convergentes entre eles em todos os aspectos no que se refere a importância da análise de ao menos três períodos para fornecer um histórico do desempenho financeiro da empresa. Desta forma, a contribuição deste estudo neste quesito permite confirmar: a análise das demonstrações contábeis para ser corretamente utilizada deve ser realizada com, no mínimo, três períodos contábeis, pois serão eles que determinarão a verificação da evolução financeira de uma empresa. Analisar apenas um período, nos levaria a uma conclusão da situação financeira atual da empresa, o que não é a base da fundamentação dessa ferramenta.

Perguntou-se aos entrevistados: Como você descreveria o processo de liberação de crédito da pessoa jurídica?

Por referencial teórico, o processo de concessão de crédito deve ser baseado numa análise completa da empresa, sendo avaliada sua estrutura financeira, seu potencial e histórico de pagadora, a sua operacionalidade e destinação do crédito, seu desempenho 
dentro do setor econômico ao qual se insere e a análise do caráter dos sócios de maneira individual.

Ao analisar as respostas, verificou-se que para esse processo é feita uma análise cadastral da empresa e uma análise de restrições da empresa e/ou de seus sócios, estas informações são inseridas em uma planilha de demonstrativos contábeis, junto à sua análise de evolução, além disso, analisa-se a forma com que a empresa está inserida no mercado, bem como em seu setor de atuação.

A comparação desta questão com o referencial teórico foi positiva.

Os resultados acima foram comparados com a pesquisa de Mondini (2005), onde este autor descreve a importância da análise cadastral da empresa, que nos dá informações sobre a situação da empresa e sócios, além das publicações acerca do setor ao qual a empresa está inserida, avaliando sua posição dentro deste setor. Essa análise é complementar a análise das demonstrações contábeis, que fornece informações sobre a saúde financeira da empresa. Identifica-se que os dados analisados nesta questão são convergentes no que se refere à importância da utilização das outras informações citadas acima.

Desta forma a contribuição deste estudo neste quesito permite confirmar que a análise de crédito em sua forma mais completa e dentro das suas possibilidades de obtenção de informação deve se valer de dados sobre o cadastro da pessoa jurídica (empresa analisada) e das pessoas físicas que a compõem (sócios), sendo relevantes por permitir a avaliação do caráter dessa instituição; a avaliação setorial também aparece como fundamental, pois o setor no qual a empresa se insere pode e deve fornecer dados sobre as perspectivas de mercado da empresa. E obviamente, a análise das demonstrações contábeis não pode ser descartada neste processo, por sua capacidade de identificar o potencial financeiro da empresa.

Perguntou-se aos entrevistados: Dentre o conjunto das demonstrações contábeis, quais são as informações indispensáveis para uma análise consistente da situação financeira de uma empresa?

O referencial teórico para esta questão informa que, com maior frequência, a análise do Balanço Patrimonial e da DRE são suficientes, pois fornecem a estrutura patrimonial da empresa, e sua evolução de resultados quando são comparados períodos suficientes de DRE. 
Ao analisar as respostas, confirmou-se que prioritariamente são considerados o Balanço Patrimonial com o Ativo e Passivo e com a Demonstração de Resultados, sendo os demais itens, quando obtidos, utilizados de forma complementar.

A comparação desta questão com o referencial teórico foi positiva.

Ao comparar os resultados acima com o que diz Assaf Neto (2010), onde o autor informa a necessidade de a análise ser realizada com o conjunto das informações geradas pela empresa periodicamente, contemplando Balanço Patrimonial, Demonstração dos Resultados, Demonstrações das Mutações do Patrimônio Líquido, Demonstração do Fluxo de Caixa, e Demonstração do Valor Adicionado, já citados neste artigo, identifica-se que os dados analisados nesta questão são convergentes, pois, de acordo com a opinião dos entrevistados, a gama de informações dadas é mais completa se a quantidade de demonstrações fornecidas for maior.

Desta forma, a contribuição deste estudo neste quesito permite confirmar que costumeiramente, a análise do balanço patrimonial e da DRE são suficientes para a análise de crédito, porém, a detenção das outras demonstrações da empresa, citadas anteriormente, permitem uma análise mais completa, sendo, portanto, muito importantes neste processo, ainda que dispensáveis.

Perguntou-se aos entrevistados: No processo de concessão de crédito, quais indicadores extraídos da análise das demonstrações contábeis são considerados os mais importantes e o que esses indicadores fornecem de informação relevante?

Ao analisar as respostas, verificou-se que houve referência a diversos indicadores: indicadores de liquidez, de endividamento e lucratividade.

Para a questão acima, foi identificado no referencial teórico uma abordagem acerca dos principais indicadores citados nas entrevistas. Identifica-se que os dados analisados nesta questão são convergentes, no que refere-se à diversidade de indicadores que são utilizados neste processo.

Desta forma, a contribuição deste estudo neste quesito permite verificar que não é possível definir obrigatoriedade na utilização de " $n$ " números de indicadores, e elencá-los por grau de importância, sendo cada indicador citado nas respostas, detentor de sua importância notória, em cada contexto. Verifica-se a importância dada aos indicadores de endividamento e liquidez, que informam sobre a capacidade de a empresa arcar com suas obrigações, mas não avaliadas de forma exclusiva. 
Questionou-se aos entrevistados: Em uma escala de 0 a 100\%, qual a sua avaliação da importância da análise das demonstrações contábeis para a definição de concessão de crédito da pessoa jurídica?

Dado o referencial teórico, a percepção dos autores é de que ao menos a análise das demonstrações contábeis corresponda a $80 \%$ ou mais da resposta ao crédito.

Ao analisar as respostas, verificou-se que em média esse percentual é de $70 \%$.

A comparação desta questão com a percepção dos autores foi negativa em um pequeno percentual. O que nos leva a identificar que existem ainda $30 \%$ que não são informados pelas Demonstrações Contábeis.

Para a questão acima, não foi encontrada literatura sobre o assunto, baseando-se a conclusão desta questão na experiência dos entrevistados. Identifica-se que os dados contábeis, de acordo com as respostas, são de extrema importância para o processo de crédito. Desta forma a contribuição deste estudo neste quesito permite confirmar que o principal item da análise de crédito é a análise das demonstrações contábeis.

Perguntou-se aos entrevistados: As decisões de concessões de crédito seguem um padrão pré-estabelecido, ou cabe à experiência do analista de crédito saber se utilizar das informações contábeis?

Os autores entendem que a experiência do analista é peça fundamental neste processo, porém seria incoerente estabelecer padrões pré-definidos de análise.

Ao analisar as respostas, verificou-se que a experiência do analista é muito importante neste processo de decisão de concessão de crédito, havendo dentro das instituições distintas metodologias de procedimentos de análise.

A comparação desta questão com o constructo foi positiva no que diz respeito à experiência dos analistas, mas verificou-se a necessidade de mais estudos sobre estas outras metodologias de análise.

Os resultados acima foram comparados com o que diz Assaf Neto (2010) sobre como a análise é utilizada de forma particular por quem faz a análise, sendo considerados não só o conhecimento técnico destes analistas, mas também sua experiência e intuição. Feita a comparação, identificou-se que os dados analisados nesta questão são convergentes, no que refere-se à importância da experiência do analista.

Desta forma, a contribuição deste estudo neste quesito permite confirmar que o feeling do analista de crédito é fator de contribuição para o processo de crédito. As 
informações por si só fornecem muitos dados sobre a empresa, e dependendo da instituição financeira, estes dados podem ser tratados por metodologias distintas, mas sempre caberá a opinião e visão do analista sobre a posição analisada.

Questionou-se aos analistas: É possível descrever brevemente, uma situação hipotética, onde através da análise das demonstrações contábeis, pode-se considerar que uma empresa não está apta a receber crédito financeiro?

Para essa questão é válido comparar os referenciais teóricos que indicam, por exemplo, a importância da verificação do grau de endividamento, e das restrições cadastrais.

Ao analisar as respostas, verificou-se que os aspectos levados em consideração, negativamente, para a decisão de crédito de uma empresa, seriam: possui Patrimônio Líquido negativo, restrições na empresa, alto grau de endividamento, má estrutura dos demonstrativos, onde hajam contas com saldos elevados sem seu devido desdobramento, demonstrações não assinadas, e consequentemente não confiáveis.

Desta forma, a contribuição deste estudo neste quesito permite confirmar que inúmeras situações podem ser decisivas no processo de crédito, mas cabe ao analista valerse de distintas fontes de informações, e variáveis. A estrutura de endividamento aparece novamente, como anteriormente citada no item de principais indicadores. Dá-se indicação a confiabilidade das informações, que também devem ser apontadas neste processo.

\subsection{Confiabilidade das Fontes de Informações Contábeis}

Perguntou-se aos entrevistados Onde são coletadas as demonstrações contábeis a serem analisadas?

Ao analisar as respostas, verificou-se que as fontes mais comuns das informações são publicações em sites, jornais, CVM, ou ainda são fornecidas pela própria empresa ou escritório de contabilidade.

Ao comparar os resultados acima com o que diz Sá (2008) sobre a origem das demonstrações, verifica-se que os analistas podem receber as informações através de dados publicados, no caso de empresas que são obrigadas a fazê-lo, ou através da entrega das demonstrações pelos próprios credores e financiadores, autenticadas nos registros comerciais ou cartórios. Ainda segundo o autor, a qualidade das informações interfere na 
conclusão do analista. Feita a comparação, identificou-se que os dados analisados nesta questão são convergentes, no que se refere diversidade das origens das informações.

Desta forma, a contribuição deste estudo neste quesito permite confirmar que existem diversas fontes de obtenção das informações contábeis, sendo cada uma delas detentora de maior ou menor grau de confiabilidade, e esse fator pode contribuir para o processo de decisão.

Questionou-se aos entrevistados: As fontes de onde provem as informações contábeis (dados extraídos de demonstrações auditadas ou de fontes oficiais - SPED contábil/Livro diário) influenciam na tomada de decisão do crédito?

Os autores acreditam que a origem da informação deve sim ser considerada em um processo de concessão de crédito onde seja avaliada a saúde financeira da empresa, por fornecer maior confiabilidade aos dados contábeis.

Ao analisar as respostas, verificou-se que esse fator é importante, por fornecer maior credibilidade às demonstrações.

Os resultados acima foram comparados com o que diz Sá (2008), quando cita que a qualidade das informações interfere na conclusão, logo, uma análise com bases não confiáveis, pode gerar uma conclusão igualmente não-confiável. Após realizada a comparação, identificou-se que os dados analisados nesta questão são convergentes, no que refere-se a confiabilidade dada por dados extraídos de fontes confiáveis.

Desta forma, a contribuição deste estudo neste quesito permite confirmar que quanto mais confiáveis forem as informações contábeis, mais confiável será a decisão de crédito. A avaliação da fonte de informação deve ser considerada, a nível de análise de risco. Não se pode analisar em igualdade de critérios uma demonstração publicada em fontes oficiais, com uma informação dada pela própria empresa, muitas vezes sem a própria assinatura do contador ou sócio da empresa.

Perguntou-se aos entrevistados: No processo de liberação de crédito, são considerados (quando existentes) o parecer de auditoria e/ou o relatório da administração? Em caso afirmativo, qual seria a influência desses dados na decisão de crédito?

Os autores acreditam que o cenário ideal seria extrair destas peças informações sobre as operações da empresa, indicações da administração sobre o futuro financeiro da empresa e informações dos auditores sobre a qualidade das informações contábeis. 
Ao analisar as respostas, verificou-se que eles são importantes na medida em que dão maiores informações sobre a empresa, tanto em questões de ressalvas dos auditores, ou em maiores informações de mercado e perspectivas fornecidas pelo relatório da administração.

Os resultados acima foram comparados com o que diz Assaf Neto (2010), segundo o qual o relatório da diretoria fornece dados da empresa de forma geral, como projeções financeiras, projeções de expansão, perspectivas de mercado, entre outros, e o parecer de auditoria fornece maior segurança na análise das demonstrações, e maior qualidade de informação. Com base nesta comparação, identificou-se que os dados analisados nesta questão são convergentes, no que se refere à existência de dados completos e a diminuição de risco acerca das informações.

Desta forma, a contribuição deste estudo neste quesito permite confirmar que esses itens são importantes quando fornecidos e complementam a análise das demonstrações, sendo o parecer de auditoria responsável por fornecer maior confiabilidade nos dados analisados, uma vez que ele vai indicar a concordância das práticas contábeis adotadas pela empresa e identificar possíveis fraudes ou incoerência nas demonstrações. O relatório da administração, por sua vez, apesar de advir de fontes internas da empresa, pode auxiliar, ainda que de maneira menos relevante, já que possui a opinião dos administradores, na verificação das perspectivas da empresa de crescimento e desenvolvimento dentro de seu setor, podendo ainda fornecer dados de projeções que podem contribuir muito para a avaliação de seu desempenho.

Inquiriu-se aos entrevistados: Em caso de análise baseada em demonstrações "não-oficiais", é levada em consideração no processo de concessão de crédito a qualidade desse documento e sua obediência às práticas contábeis? Esse fator causa algum impacto no processo de decisão do crédito?

A opinião dos autores é de que o ideal seria levar em consideração a qualidade das informações, se estão de acordo com as práticas contábeis aceitas, evitando ou diminuindo o risco de fraude nas informações.

Ao analisar as respostas, verificou-se que é importante a utilização de informações oficiais, por indicarem um risco menor para a análise. Para demonstrativos advindos da empresa diretamente, se faz necessária a assinatura do sócio e do contador da empresa que 
possam validar as informações, sendo necessária também a verificação da utilização das práticas contábeis corretas por essas empresas.

A comparação desta questão com o a opinião dos autores foi positiva.

Para a questão acima, não foi encontrada literatura sobre o assunto, baseando-se a conclusão desta questão na experiência dos entrevistados. Sá (2008), diz que a qualidade das informações interfere na conclusão, logo, uma análise com bases não confiáveis pode gerar uma conclusão igualmente não confiável. Desta forma, identificou-se que os dados analisados nesta questão são convergentes, no que se refere à confiabilidade dada por dados extraídos de fontes confiáveis.

Desta forma, a contribuição deste estudo neste quesito permite confirmar que a utilização de informações oficiais contribui para diminuir o risco de análise. Quando se utilizam de informações não oficiais, como as advindas das próprias empresas ou escritórios de contabilidade, a análise fica exposta ao risco de decisão de crédito equivocada. Caberia ao analista, nestes casos, validar as informações dadas, avaliando se as práticas contábeis estão coerentes e se os demonstrativos possuem as assinaturas dos responsáveis por sua elaboração.

Questionou-se aos entrevistados: Considerando a sua experiência em torno da análise e liberação de crédito, você diria que a análise das demonstrações é um critério válido e seguro para a avaliação da empresa? É possível dizer que ela é um elemento com alto grau de risco, havendo convergência no que se refere ao risco de avaliação baseada apenas nas demonstrações, sendo complementado pela informação da necessidade de confiabilidade nas fontes contábeis?

Os autores acreditam que a análise das demonstrações contábeis pode ser considerada de risco, quando avaliada de forma exclusiva e isolada, devendo ser analisada de forma conjunta com outros elementos para ser considerado um critério válido e seguro.

Ao analisar as respostas, verificou-se que a análise é considerada com maior risco, quando a fonte de informação não é confiável, indicando inclusive o fato de empresas com demonstrações publicadas serem mais confiáveis. Durante as entrevistas, foi comentado por um dos respondentes a necessidade de se verificar não apenas os números da empresa, mas todas as informações sobre a estrutura da empresa.

A comparação desta questão com a opinião dos autores foi positiva no que refere-se à utilização de outros elementos de análise de crédito. 
Para a questão acima, não foi encontrada literatura sobre o assunto, baseando-se a conclusão desta questão na experiência dos entrevistados. Mais uma vez, identifica-se a necessidade da qualidade das informações.

Desta forma, a contribuição deste estudo neste quesito permite confirmar que a análise de crédito para expor maior confiabilidade deve ser baseada em dados oficiais, e para ser completa e dar mais veracidade à avaliação da empresa, deve-se valer de outros elementos ora citados na conclusão da Questão 2 deste artigo.

\subsection{Outros Fatores Presentes no Processo de Crédito}

Questionou-se aos entrevistados: Em uma decisão de crédito são avaliados os dados contábeis visando apenas identificar a situação presente da saúde financeira de uma empresa, ou buscam-se avaliar suas tendências econômicas passadas e futuras? Caso afirmativo, de que forma isso é medido e/ou avaliado?

A opinião dos autores é de que a análise de crédito deve-se basear em todas as possibilidades financeiras de uma empresa. Avaliar apenas o presente pode ser considerado superficial, não representando a realidade de uma empresa. Deve-se sempre verificar seu passado, e suas tendências futuras.

Ao analisar as respostas, verificou-se que há necessidade de avaliação tanto do passado da empresa, como suas perspectivas futuras, não devendo apenas ser avaliada sua estrutura presente.

A comparação desta questão com a opinião dos autores constructo foi positiva.

Os resultados acima foram comparados com o que diz Assaf Neto (2010), quando indica que através da análise de balanços é possível extrair informações sobre a situação passada, presente e futura da empresa. Após a comparação, identificou-se que os dados analisados nesta questão são convergentes.

Desta forma, a contribuição deste estudo neste quesito permite confirmar que a análise das demonstrações contábeis deve contemplar a avaliação das tendências passadas e futuras da empresa, não só o seu presente. Sendo assim, identifica-se a importância da realização de análise comparativa de períodos contábeis, pois através da análise de apenas um período, não seria possível verificar as tendências passadas que conduziram a empresa a sua atual situação. Além disso, através de sua estrutura patrimonial, seus dados de 
operacionalidade, suas informações e projeções financeiras e suas perspectivas de mercado, pode-se avaliar as tendências futuras da empresa, por isso, é também avaliada a qualidade de seus endividamentos, e a finalidade da atual proposta de crédito para verificar se a empresa futuramente possui perspectivas de expansão.

Questionou-se aos entrevistados: Quais são as outras avaliações, além da análise das demonstrações contábeis, que são relevantes numa análise de crédito. Dentre esses itens, qual, em sua opinião, seria o principal critério?

Os autores acreditam que a análise de crédito deve se valer de dados financeiros que permitam avaliar as condições atuais da empresa, em conjunto com dados que permitam analisar seu histórico passado e perspectivas futuras, levando em conta sua operacionalidade, o mercado ao qual se insere e as características de seu negócio, além disso, devem avaliar também o caráter dos sócios e suas características como pagadoras. Enfim, o Analista deve se valer de todos os critérios possíveis para finalizar sua decisão.

Ao analisar as respostas, verificou-se que há necessidade de análise do caráter e experiência dos sócios, análise do setor ao qual a empresa está inserida, o ramo de atividade da empresa, irregularidade e restrições da empresa, grau de endividamento e pagamento dessas dívidas, bem como as perspectivas de expansão, ou não, da empresa.

A comparação desta questão com a opinião dos autores foi positiva.

Ao comparar os resultados acima com a pesquisa de Mondini (2005), conforme já citado na avaliação da Questão 2 deste artigo, identificou-se que os dados analisados nesta questão são convergentes, no que refere-se à diversidade de dados analisados no processo de crédito.

Desta forma, a contribuição deste estudo neste quesito permite confirmar que a análise de crédito vale-se, além de informações contábeis, de informações cadastrais, setoriais e de ramo de atividade da empresa. É importante verificar todos os quesitos de operacionalidade da empresa, verificando suas perspectivas e caráter de potencial pagadora. Para essa situação, é válido citar a questão onde a análise de demonstrações obteve em média $70 \%$ do grau de participação em um processo de crédito, por isso podemos considerá-lo aqui, de maneira geral, como o faor principal, no entanto, ao se avaliar a questão a seguir, é possível perceber que, em algumas situações, nem sempre este fator será o decisivo. 
Questionou-se aos entrevistados: A análise das demonstrações contábeis pode ser considerada uma ferramenta confiável, válida por si só, ou sempre dependerá de outros fatores num processo de decisão de crédito?

Os autores opinam que, para uma decisão com menor grau de risco e com alicerces mais coerentes, a análise das demonstrações contábeis não pode ser considerada como único fator.

Ao analisar as respostas, verificou-se que para esse processo não podem ser avaliados apenas os demonstrativos contábeis, mas sim todo o conjunto de informações acerca da empresa.

A comparação desta questão com a opinião dos autores foi positiva, havendo convergência entre eles em todos os aspectos.

Para a questão acima, não foi encontrada literatura sobre o assunto, baseando-se a conclusão desta questão na experiência dos entrevistados. Pode ser referenciado neste item, o que foi exposto na conclusão da Questão 2, que aborda o processo de crédito que discorre sobre os itens que compõem a análise de crédito.

Desta forma, a contribuição deste estudo neste quesito permite confirmar que a análise das demonstrações contábeis não pode ser avaliada de forma isolada, sendo os demais itens de avaliação de crédito de extrema importância nesta decisão, pois fornecem dados complementares que fazem com que os dados contábeis não sejam confiáveis por si só.

Questionou-se aos entrevistados: Na ocasião de esses "outros fatores" serem considerados favoráveis, e a análise de balanço demonstrar uma má situação financeira da empresa, isso pode ser decisivo para uma decisão de não concessão de crédito, ou sempre serão levadas em consideração possíveis expectativas de melhora financeira?

Os autores acreditam que as variáveis financeiras são de extrema importância, mas devem ser avaliadas sempre em conjunto com as demais variáveis que envolvem o passado e o futuro da empresa. Possibilidades de recuperação financeira devem ser avaliadas. Nem sempre elas serão suficientes para conceder resposta positiva, mas ainda assim, devem ser consideradas em uma decisão. 
Ao analisar as respostas, verificou-se que para o processo de decisão de crédito, sempre serão levados em consideração todos os aspectos da empresa, não sendo critério decisivo o fato de ela estar com uma situação financeira desfavorável. Sempre se levará em conta o histórico da empresa, e suas perspectivas futuras.

A comparação desta questão com a opinião dos autores foi positiva, havendo convergência entre elas em todos os aspectos.

Para a questão acima, não foi encontrada literatura sobre o assunto, baseando-se a conclusão desta questão na experiência dos entrevistados.

Desta forma, a contribuição deste estudo neste quesito permite confirmar que a análise dos demais itens de avaliação de crédito, que não apenas a análise das demonstrações contábeis, pode influenciar, e muitas vezes ser fator decisivo numa decisão de crédito. A análise financeira nem sempre será fator de decisão neste processo. Avaliação do caráter da empresa e sócios, perspectivas de melhoria financeira, de crescimento da empresa, ou até mesmo de crescimento do setor no qual a entidade está inserida, podem ser ponto chave na concessão de crédito. Esses fatores, quando analisados de forma coerente, podem indicar a diminuição do risco da operação, ainda que a situação financeira da empresa não seja favorável.

\section{CONCLUSÕES}

Este capítulo tem por finalidade apresentar o resultado do trabalho de pesquisa que foi realizado através de entrevistas com especialistas (Analistas) da área de crédito.

Um dos objetivos específicos proposto para este trabalho foi identificar o que a análise das demonstrações contábeis fornece para a análise de crédito e qual a importância dessas informações.

Com base nos resultados desta pesquisa e em comparação com outros estudos já realizados, é possível concluir que a análise das demonstrações contábeis fornece uma boa visão da estrutura financeira da empresa, sendo através dela possível verificar a evolução patrimonial da empresa e seu grau de endividamento, que serão fundamentais na decisão de crédito. Por meio das Demonstrações Contábeis, também é possível avaliar o grau de lucratividade da empresa, analisando suas perspectivas de crescimento ou não, e seus indicadores de liquidez, que permitirão avaliar se a empresa tem estrutura para honrar com 
seus compromissos. É importante ressaltar que, dentro das perspectivas dos entrevistados, a análise das demonstrações contábeis representa, em média, $70 \%$ da decisão do processo de crédito, confirmando dessa maneira sua relevância e a necessidade de essa análise ser realizada com bases confiáveis.

Outro objetivo específico proposto para este trabalho foi identificar quando as informações são consideradas confiáveis e analisar se a fonte da demonstração contábil contribui para sua confiabilidade, ou não.

Com base nos resultados desta pesquisa e em comparação com outros estudos já realizados, é possível concluir que a fonte da informação contábil é de extrema importância para uma análise mais confiável, devendo ser levado em consideração no processo de concessão de crédito. Empresas com obrigatoriedade à publicação das demonstrações contábeis fornecem maior confiabilidade para esse processo, já que seus demonstrativos seguem padrões mais confiáveis e com maior facilidade de interpretação. Por outro lado, empresas que não possuem essa obrigatoriedade, devem buscar fornecer demonstrativos assinados por contador e sócio da empresa e procurar adotar a maior coerência possível com as práticas contábeis, para que suas demonstrações possam fornecer maior confiança.

Outro objetivo específico proposto para este trabalho foi verificar se existem outros fatores a serem avaliados num processo de crédito e a participação da análise das demonstrações contábeis neste contexto.

Com base nos resultados desta pesquisa e em comparação com os outros estudos já realizados, é possível concluir que a análise das demonstrações contábeis fornecem dados de extrema importância para o processo de concessão de crédito, porém, não pode ser considerada de forma exclusiva para essa tomada de decisão. Para a decisão de conceder ou não crédito para uma empresa, deve ser levado em consideração outros fatores, dentre os quais os principais identificados nesta pesquisa são: análise de grau de endividamento da empresa, análise de restrições e caráter da empresa e dos sócios, análise do ramo de atividade da empresa, análise de informações cadastrais, análise do setor de atividade no qual a empresa está inserida, finalidade do crédito, ou seja, qual a destinação do crédito solicitado pela empresa, verificação das perspectivas de crescimento analisando não só seus demonstrativos contábeis, mas suas propostas de operacionalidade futuras.

Este trabalho lançou três pares de proposições, que podem ser analisados da seguinte maneira: 
Para o primeiro par de proposições, tem-se:

P1- A análise de demonstrações contábeis fornece informações importantes e decisivas em um processo de crédito.

P2- A análise de demonstrações contábeis não fornece informações importantes e decisivas num processo de crédito.

Diante dos resultados apresentados, a proposição P1 é ACEITA. A razão para esta aceitação é a verificação de que a análise de demonstrações contábeis, apesar da necessidade de estar atrelada a outros fatores, representa em média $70 \%$ da relevância no processo de concessão de crédito, segundo os entrevistados.

Diante dos resultados apresentados, a proposição P2 é REJEITADA. A razão para esta rejeição é a oposição ao exposto no parágrafo anterior, tendo em vista a importância desta análise no processo de crédito.

Para o segundo par de proposições, tem-se:

P3- As informações geradas pela análise das demonstrações contábeis são consideradas confiáveis, e por isso fundamental para o processo de concessão de crédito.

P4- As informações geradas pela análise das demonstrações contábeis não são consideradas confiáveis, e por isso não são fundamentais para o processo de concessão de crédito.

Diante dos resultados apresentados, a proposição P3 é ACEITA, porém de forma parcial. A razão para esta aceitação parcial é a veracidade na afirmação da referida análise ser fundamental para o processo de crédito na ocasião de suas informações serem confiáveis. Essa conclusão se dá, pela verificação ao longo do trabalho, de que a confiança das informações geradas pela análise das demonstrações contábeis estará atrelada à fonte dessas demonstrações.

Diante dos resultados apresentados, a proposição P4 é REJEITADA, mas também de forma parcial. A razão para essa rejeição parcial se deve ao fato de que não se pode dizer que a análise das demonstrações contábeis não seja fundamental no processo de crédito, porém nem sempre é possível identificar essa análise como confiável por si só, cabendo sempre esse critério ao grau de confiança da fonte das informações contábeis.

Para o terceiro par de proposições, tem-se:

P5- Existem diversos outros fatores a serem considerados de forma relevante neste processo de crédito. 
P6 - Os outros fatores analisados não fornecem informações decisivas neste processo, sendo apenas fatores complementares.

Diante dos resultados apresentados, a proposição P5 é ACEITA. A razão para essa aceitação se dá ao fato da constatação através das entrevistas de que o processo de crédito possui diversos outros fatores de análise, que devem ser atrelados à análise das demonstrações contábeis em um processo de concessão de crédito.

Diante dos resultados apresentados, a proposição P6 é REJEITADA. A razão para essa rejeição se dá pela verificação de que os demais fatores de análise de crédito têm tanta importância quanto à análise das demonstrações contábeis, e fornecem dados que muitas vezes podem ser decisivos neste processo.

O assunto análise das demonstrações contábeis é um fenômeno considerado antigo no campo de estudo da Ciência Contábil. É sabido que sua funcionalidade está atrelada ao fornecimento de dados sobre a empresa para os acionistas, fornecedores, credores em geral, inclusive instituições financeiras, e também para investidores.

As questões pesquisadas neste trabalho procuram contribuir para a compreensão desta ferramenta no campo de análise do processo de concessão de crédito, visando identificar seu grau de relevância para essa tomada de decisão.

Sendo assim, este trabalho contribui para a sociedade e o meio acadêmico com seus resultados e análises.

\section{REFERÊNCIAS}

ABRAMO, Perseu. Pesquisa em ciências sociais. HIRANO,sedi(cood) Pesquisa Social : projeto e planejamento._São Paulo: TA Querioz,1988

ASSAF NETO, Alexandre. Estrutura e Análise de Balanços: Um Enfoque EconômicoFinanceiro. $9^{a}$ edição. São Paulo: Atlas, 2010.

BENEDICTO, Gideon C. de; PADOVEZE, Clóvis L. Análise das Demonstrações Financeiras. São Paulo: Thomson, 2005.

COOPER, Donald R; SCHINDLER, Pamela S. Métodos de pesquisa em administração. 7ed. Porto Alegre: Bookman, 2003 
FERRARI, Ed Luiz. Análise de Balanços: Teoria e 300 Questões. $2^{a}$ edição. Rio de Janeiro: Elsevier, 2006.

GIL,Antonio Carlos. Como elaborar projetos de pesquisa. 3.ed. São Paulo: Atlas,1996

GODOY,Arilda Schmidt. Introdução à pesquisa qualitativa e suas possibilidades. Revista de Administração de empresas São Paulo, v.35, n.2, p.-57-63, mar/abr.1995

HAIR, Joseph F.BABIN, Barry, MONEY, Arthur H., SAMOUEL, Phillip. Fundamentos de métodos de pesquisa em administração. Porto Alegre: Bookman, 2005

IUDÍCIBUS, Sérgio de. Análise de Balanços. 10ª edição. São Paulo: Atlas, 2009.

MARION, José Carlos. Análise das Demonstrações Contábeis: Contabilidade Empresarial. $3^{a}$ edição. São Paulo: Atlas, 2006.

MARTINS, Gilberto de Andrade. Estudo de caso: Uma estratégia de pesquisa. São Paulo, 2008 .

MARTINS, Gilberto de Andrade; THEÓPHILO, Carlos Renato. Metodologia da investigação científica para Ciências Sociais Aplicadas. São Paulo: Atlas, 2007. 225 p. ISBN 9788522447961

MATARAZZO, Dante C. Análise Financeira de Balanços. 6ª edição. São Paulo: Atlas, 2003.

MONDINI, Luiz Carlos. Análise de Crédito de Empresas Desobrigadas da Emissão de Balanço/Balancete Patrimonial - Uma Contribuição às Instituições de Crédito. 2005. Dissertação (mestrado em Controladoria e Contabilidade Estratégica) - UniFecap, São Paulo, 2005.

PERERA, Luiz Carlos Jacob. Decisões de Crédito para Grandes Corporações. 1998. Tese (doutorado) - USP, São Paulo, 1998.

POHLMANN,Marcelo Coletto, Contribuição ao estudo da classificação interdisciplinar da pesquisa tributária e do impacto da tributação na estrutura de capital das empresas no Brasil. Tese (de doutoramento em Ciências contábeis) FEA USP 2005 
ROESCH,Sylvia M. A. A dissertação de mestrado em Administração: proposta de uma tipologia. Revista de Administração da USP, São Paulo v.31, n.1, p.75-83, janeiro/marco,1996

SÁ, Antônio Lopes de. Moderna Análise de Balanços ao Alcance de Todos. Curitiba: Juruá, 2008.

TELLES, Renato. Considerações sobre tipificação da investigação Cientifica e Pesquisa Qualitativa. Revista Álvares Penteado, São Paulo, V. 3, n. 6, jun 2001, pg 83-93

YIN, Robert K.. Estudo de caso: planejamento e métodos. 3. ed. Porto Alegre: Bookmam, 2005. 